\title{
Kajian Kelayakan Penempatan Solar Pond sebagai Sumber Energi Terbarukan di Jeneponto
}

\author{
Nur Fadliah Baso ${ }^{* 1,}$ Indar Chaerah Gunadin ${ }^{1}$, Yusran $^{1}$ \\ ${ }^{1}$ Departmen Teknik, Fakultas Teknik Elektro, Universitas Hasanuddin, \\ Jl. Poros Malino Km.6, Bontomarannu, Gowa, Sulawesi Selatan, 92171 \\ *Email: nfadliahb@gmail.com
}

\begin{abstract}
Abstrak
Energi listik merupakan kebutuhan manusia yang sangat penting karena selain berfungsi dalam penerangan, energi listrik juga sangat berperan dalam berbagai aktivitas manusia lainnya. Dengan seiring waktu, bahan baku pembangkit tenaga listrik dari fosil juga semakin menipis. Sudah selayaknya kebutuhan energi yang memanfaatkan energi fosil berganti menjadi energi terbarukan. Salah satu pemanfaatan energi terbarukan yang potensinya sangat besar di Indonesia adalah energi berasal dari energi laut yang dinamakan solar pond. Energi dari solar pond sangat dipengaruhi oleh beberapa faktor yaitu salinitas, temperatur udara dan radiasi matahari. Penelitian ini akan difokuskan untuk mencari potensi solar pond di Jeneponto yang memiliki curah matahari cukup besar dan ketersediaan bahan baku air garam yang melimpah. Metode yang digunakan yaitu dengan menganalisa nilai dari model matematis radiasi matahari horizontal harian, temperatur udara, kecepatan angin, kelembaban relatif, dan tekanan atmosfir selama 22 tahun terakhir yang diselesaikan dengan menggunakan MATLAB. Hasil penelitian ini akan menunjukkan potensi untuk penerapan solar pond di Jeneponto yang dapat di aplikasikan di berbagai bidang seperti pembangkit energi listrik, proses pemanasan industri, desalinasi dan pemanasan konversi biomass.
\end{abstract}

\begin{abstract}
Electrical energy is one of the important human needs because in addition to function in lighting, electrical energy also plays important role in various human activities. With times, the raw materials for power generation from fossils also decreases. It is now considered the time to switch to renewable energy. One of the renewable energy utilization with high potency in Indonesia is the energy derived from oceanic energy called Solar Pond. Energy from Solar Pond is highly influenced by several factors including saliniity, air temperature and solar radiation. This study will be focused to find potentials of Solar Pond in Jeneponto, a region with fairly high solar radiation intensity and abundant salt water availability. Method used in this study was by analyzing the values of the mathematical model of daily horizontal solar radiation, air temperature, wind speed, relative humidity, and atmospheric pressure for the last 22 years which were finalized using MATLAB. These study findings will indicate the potential for solar pond application in Jeneponto which can be applied in various fields including power generation, industrial heating process, desalination and heating for biomass conversion.
\end{abstract}

Kata Kunci : Potensi, Solar Pond, Energi Terbarukan

\section{Pendahuluan}

Wilayah laut Indonesia mempunyai luas tiga kali lebih besar dari luas daratan, namun kegiatan pemanfaatan energi laut belum berkembang. Potensi dari energi laut yang masih belum begitu dikembangkan di Indonesia yaitu sumber energi yang berasal dari solar pond. Salah satu cara untuk menangkap energi matahari adalah dengan menggunakan teknologi solar pond, dibandingkan dengan yang lainnya, metode penggunaan energi panas matahari untuk pembangkit tenaga listrik dinilai lebih efisien [1]. Solar pond merupakan kolam air garam yang mampu menyimpan radiasi matahari dan energi panas untuk selang waktu yang lama [2]. Solar pond telah diusulkan sebagai teknologi yang sederhana dan ekonomis dalam mengumpulkan dan menyimpan energi panas dalam skala besar [3]. Umumnya solar pond memiliki luas $2000 \mathrm{~m}^{2}$ sampai $250.000 \mathrm{~m}^{2}$ dengan kedalaman $4 \mathrm{~m}$. Penerapan solar pond dapat di aplikasikan di berbagai bidang seperti pembangkit energi listrik, proses pemanasan industri, desalinasi dan pemanasan konversi biomass.

Untuk pembangkit tenaga listrik, teknologi ini sudah lama di gunakan di negara-negara maju 
seperti Amerika Serikat, Israel dan Australia. Di Amerika Serikat memiliki El Paso solar pond yang beroperasi pada tahun 1986 dengan luas $3200 \mathrm{~m}^{2}$ yang menghasilkan $70 \mathrm{~kW}$. Di Israel memiliki Beit Haarava solar pond beroperasi pada tahun 1987 dengan luas $250.000 \mathrm{~m}^{2}$ yang menghasilkan 5 MW. Di Australia memiliki Alice Spring pond yang beroperasi pada tahun 1983 dengan luas $2000 \mathrm{~m}^{2}$ yang menghasilkan 20 $\mathrm{kW}$.

Sedangkan untuk proses pemanasan industri di India memiliki Bhuj solar pond yang beroperasi pada tahun 1993 dengan luas $6000 \mathrm{~m}^{2}$ yang menyuplai 80.000 liter air panas per hari. Pemanfaatan energi yang berasal dari solar pond tentunya merupakan aset jangka panjang di Indonesia.

Pada penilitian ini penulis melakukan analisa tentang data rata-rata; radiasi matahari horizontal harian, temperatur udara, kecepatan angin, kelembaban relatif, dan tekanan atmosfir selama 22 tahun terakhir yang bersumber dari situs web NASA. Data yang diperoleh kemudian diolah lagi untuk medapatkan nilai temperatur storage zone (LCZ) pada solar pond. Pemanfaatan energi panas LCZ dilakukan setelah temperatur pada LCZ telah mencapai temperatur $70{ }^{\circ} \mathrm{C}$. Nilai temperatur ini yang kemudian dapat digunakan diberbagai bidang seperti pembangkit tenaga listrik, proses pemanasan industri, desalinasi dan pemanasan konversi biomass. Teknologi ini sangat di usulkan untuk daerah-daerah tropis yang berada di pesisir pantai karena selain praktis, teknologi ini juga merupakan teknologi yang murah dan ramah lingkungan. Dari pertimbangan tersebut sehingga penulis memilih daerah Jeneponto di Sulawesi Selatan untuk melakukan riset penelitian.

Struktur penulisan penelitian ini terbagi atas beberapa bagian. Pada bagian pertama membahas tentang pendahuluan, bagian kedua menjelaskan tentang teori dasar solar pond, bagian ketiga membahas tentang metodologi penelitian, bagian keempat menjabarkan hasil dan pembahasan, dan bagian kelima menyimpulkan inti dari hasil penelitian dari penelitian yang telah dilakukan.

\section{Solar Pond}

Solar pond merupakan kolam air garam yang berfungsi untuk mengumpulkan energi panas matahari yang akan dikonversikan lagi kedalam bentuk energi listrik. Teknologi ini merupakan teknologi mendasar dan sangat mudah digunakan dengan lahan yang cukup dan desain yang tepat. Ukurannya pun bervariasi tergantung dari kebutuhannya.

Pada dasarnya air dibawah terik matahari dapat menyerap panas matahari secara alami. Ketika energi panas matahari masuk kedalam air, air akan menjadi panas dan bagian air yang panas densitasnya akan turun karena terjadi pemuaian pada air sehingga air yang panas akan naik ke permukaan dan air yang lebih dingin akan berada didasar. Akibat adanya kontak antara air panas dan udara permukaan terjadi pelepasan kalor secara konduksi dan konveksi pada air panas sehingga kalor pada air terbuang sia-sia.

Agar panas didalam air tadi tidak terbuang sia-sia maka dimasukkan garam kedalam air. Ketika air yang diberi garam dipanaskan, garam mudah larut didalam air sehingga air panas yang tadinya ringan menjadi lebih berat karena larutan garam membuat densitas air menjadi lebih berat dan air yang lebih dingin naik ke permukaan karena lebih ringan.

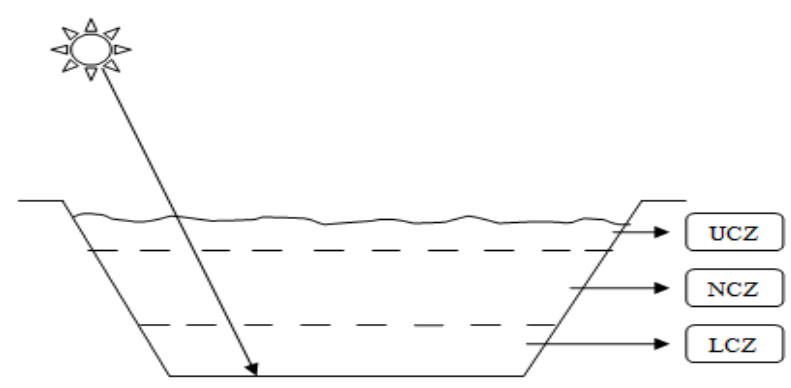

Gambar 1. Pemodelan layer solar pond

Dalam pemodelan layer solar pond, terbagi atas 3 bagian yaitu :

a. Upper Convective Zone (UCZ) / Upper Zone memiliki kedalaman 0,3 - 0,5 m, menerima radiasi matahari secara langsung, memilki salinitas dan temperatur rendah yang merata pada seluruh kedalamannya.

b. Non-Convective Zone (NCZ) / Gradient Zone memiliki kedalaman $1-1,5 \mathrm{~m}$, memilki distribusi salinitas dan temperatur yang 
bervariasi sebagai fungsi kedalaman. Semakin meningkat kedalaman pada NCZ semakin besar nilai salinitas dan temperaturnya.

c. Lower Convective Zone (LCZ) / Storage Zone memiliki kedalaman $1,5-2 \mathrm{~m}$, memiliki nilai salinitas dan temperatur yang konstan serta merata pada seluruh kedalamannya. Daerah ini berfungsi sebagai zona penyimpanan panas dari solar pond, dimana temperatur LCZ dapat dimanfaatkan sesuai keperluannya.

Energi yang dihasilkan solar pond sangat tergantung pada salinitas, temperatur udara dan juga radiasi matahari.

\section{Metodologi Penelitian}

3.1 Studi Area

Pemilihan wilayah berada di Sulawesi Selatan yakni Jeneponto pada lintang 5³5'17.5"S 119³3'53.9"E karena daerah tersebut merupakan daerah penghasil garam dan memiliki potensi panas untuk dieksplorasi. Salinitas merupakan salah satu parameter penting yang berfungsi untuk menangkap panas dalam solar pond. Semakin tinggi nilai salinitas dalam solar pond maka semakin besar panas yang dihasilkan [4,5]. Pada Gambar 2 menujukkan peta daerah Jeneponto di Sulawesi Selatan.

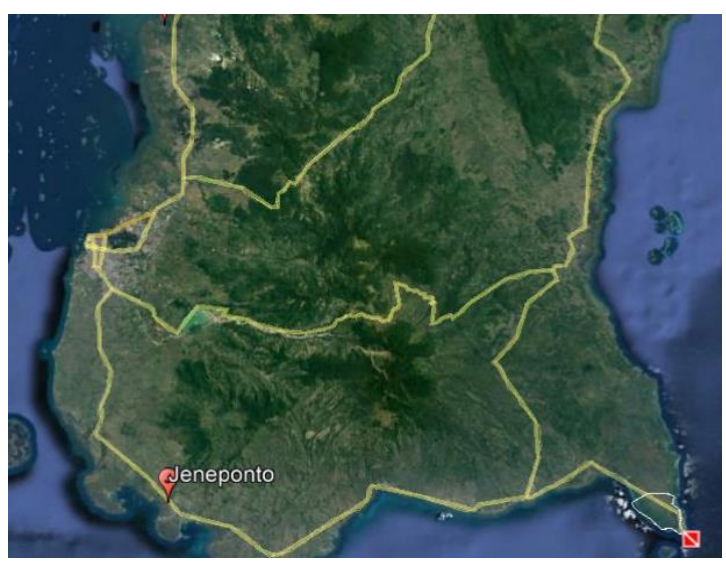

Gambar 2. Peta daerah jeneponto.

Sumber data diperoleh dari situs web NASA yang merekam data rata-rata; radiasi matahari horizontal harian, temperatur udara, kecepatan angin, kelembaban relatif, dan tekanan atmosfir selama 22 tahun terakhir [6]. Data yang diperoleh kemudian diolah lagi untuk medapatkan nilai temperatur storage zone dalam solar pond.
Tabel 1. Nilai parameter di jeneponto

\begin{tabular}{|c|c|c|c|c|c|}
\hline Bulan & $\begin{array}{c}\text { Radiasi } \\
\text { Matahari } \\
\text { Harian } \\
\left(\mathbf{k W h} / \mathbf{m}^{2} /\right. \\
\text { day) }\end{array}$ & $\begin{array}{c}\text { Temperat } \\
\text { ure } \\
\text { Udara } \\
\left(\begin{array}{ll}{ }^{\circ} & \mathrm{C}\end{array}\right)\end{array}$ & $\begin{array}{c}\text { Kecepat } \\
\text { an } \\
\text { Angin } \\
(\mathbf{m} / \mathbf{s})\end{array}$ & $\begin{array}{c}\text { Kelemba } \\
\text { ban } \\
\text { Relatif } \\
(\%)\end{array}$ & $\begin{array}{c}\text { Tekan } \\
\text { an } \\
\text { Atmos } \\
\text { fir } \\
\text { (kPa) }\end{array}$ \\
\hline Januari & 4.57 & 26.4 & 4.36 & 81.1 & 100 \\
\hline Februari & 4.84 & 26.3 & 4.43 & 80.3 & 100 \\
\hline Maret & 5.75 & 26.4 & 3.29 & 81.5 & 100 \\
\hline April & 5.91 & 26.6 & 3.36 & 80.9 & 100 \\
\hline Mei & 5.97 & 26.6 & 4.76 & 79.4 & 100 \\
\hline Juni & 5.67 & 26.1 & 5.46 & 79.0 & 100 \\
\hline $\begin{array}{c}\text { Juli } \\
\text { August }\end{array}$ & 5.95 & 25.7 & 5.92 & 76.6 & 100 \\
\hline $\begin{array}{c}\text { us } \\
\text { Septem }\end{array}$ & 6.70 & 25.8 & 6.09 & 72.7 & 100 \\
\hline ber & 7.22 & 26.3 & 5.59 & 71.5 & 100 \\
\hline $\begin{array}{c}\text { Oktober } \\
\text { Novem } \\
\text { ber }\end{array}$ & 7.05 & 26.7 & 4.25 & 73.7 & 100 \\
\hline $\begin{array}{c}\text { Desemb } \\
\text { er }\end{array}$ & 4.75 & 26.5 & 3.46 & 80.4 & 100 \\
\hline
\end{tabular}

\subsection{Model Matematis}

Rugi panas merupakan faktor terpenting yang mempengaruhi kinerja solar pond. Rugi panas dapat termasuk rugi konvektif, rugi radiasi, penguapan dan rugi sisi [7]. Pada Gambar 3 menunjukkan keseimbangan panas di upper zone.

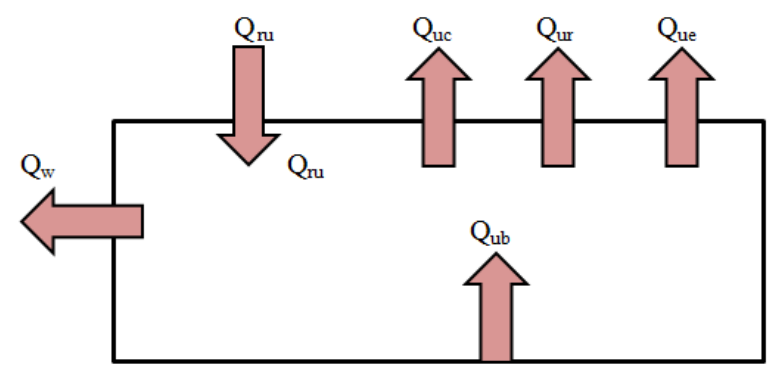

Gambar 3. Keseimbangan panas di upper zone

Persamaan untuk keseimbangan panas pada upper zone dapat ditulis sebagai :

$$
\begin{aligned}
& \rho_{u} C_{p u} A_{u} X_{u} \frac{d T u}{d t}=Q_{r u}+Q_{u b}-Q_{u c}-Q_{u r} \\
& \text { - } Q_{u e}-Q_{w}
\end{aligned}
$$

Sisi kiri persamaan (1) mewakili akumulasi panas di zona konvektif bagian atas. Untuk sisi kanan persamaan, $Q_{w}$ adalah rugi panas melalui 
dinding kolam. Dalam penelitian ini $Q_{w}=0$ (misalkan tembok itu terisolasi dengan baik) [8]. Persamaan (1) yang mewakili konservasi energi di UCZ dapat ditulis ulang sebagai:

$$
\begin{aligned}
& \rho_{u} C_{p u} A_{u} X_{u} \frac{d T_{u}}{d t}=A_{u}\left[Q_{r u}+\frac{\left[T_{s}-T_{u}\right]}{\frac{1}{h_{1}}+\frac{X_{N C Z}}{K_{W}}+\frac{1}{h_{2}}}-\right. \\
& \left\{(5.7+3.8 v)\left[T_{u}-T_{a}\right]\right\}-4.708 \times 10^{-8}\left\{T_{u}^{4}-\right. \\
& \left.\left.\left[0.0552\left(T_{a}\right) 1.5\right] 4\right\}-\left[\lambda h_{c}\left(P_{u}-P_{a}\right) /\left[\left(1.6 c_{s} P_{a t m}\right)\right]\right]\right]
\end{aligned}
$$

Rugi panas yang terjadi di storage zone berasal dari perpindahan panas secara konduksi. Isolasi yang tepat dapat digunakan untuk sisi samping dan bagian bawah storage zone guna memperbaiki kinerja storage zone. Gradient zone juga dapat mempengaruhi kinerja dengan menghalangi hilangnya panas ke atas dari storage zone ke upper zone. Pada Gambar 4 menunjukkan keseimbangan panas di storage zone.

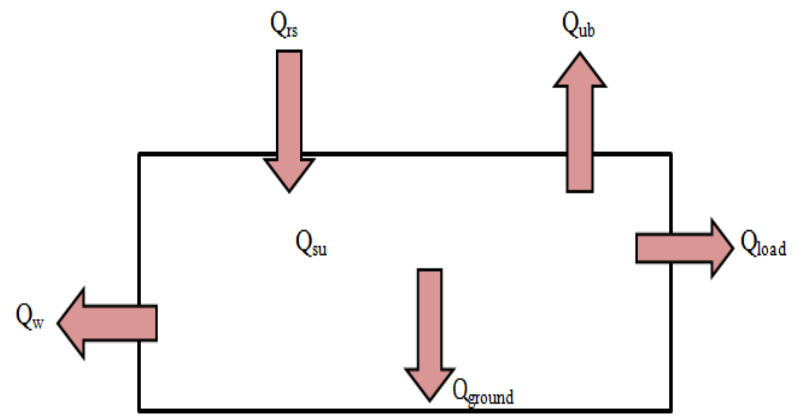

Gambar 4. Keseimbangan panas di storage zone

Persamaan untuk keseimbangan panas pada storage zone dapat ditulis sebagai :

$\rho_{l} C_{p l} A l X l \frac{d T_{s}}{d t}=Q_{r s}-Q_{u b}-Q_{\text {ground }}-Q_{\text {load }}-Q_{w}$

Hal ini diasumsikan bahwa pemanasan pada solar pond dimulai dengan tidak ada beban $Q_{\text {load }}$ $=0$. Sebagai tambahan, diasumsikan bahwa $Q_{w}=$ 0. Persamaan (3) yang mewakili konservasi energi di LCZ dapat ditulis ulang sebagai:

$$
\rho_{l} C_{p l} A l X l \frac{d T_{s}}{d t}=A_{l}\left[Q r s-\frac{\left[T_{s}-T_{u}\right]}{\frac{1}{h_{1}}+\frac{X_{N C Z}}{K_{W}}+\frac{1}{h_{2}}}\right]-\frac{A_{b}\left[T_{s}-T_{g}\right]}{\frac{1}{h_{3}}+\frac{X_{g}}{K_{g}}+\frac{1}{h_{4}}}
$$

Rincian lebih lanjut untuk setiap parameter dalam Persamaan (2) dan Persamaan diberikan oleh Jerome, Ahmed, Wongsakorn [7] dan Assad, Hazim, Alasdir [8].

\section{Hasil dan Pembahasan}

Berdasarkan data NASA, Jeneponto memiliki radiasi yang baik. Dari pengamatan yang dilakukan maka data radiasi di Jeneponto dapat dilihat pada Tabel 2 sebagai berikut :

Tabel 2. Data radiasi jeneponto

\begin{tabular}{lc}
\hline \multicolumn{1}{c}{ Bulan } & $\begin{array}{c}\text { Radiasi Jeneponto } \\
\left(\mathbf{M J} / \mathbf{m}^{\mathbf{2}} \text { /hari }\right)\end{array}$ \\
\hline Januari & 16.452 \\
\hline Februari & 17.424 \\
\hline Maret & 20.700 \\
\hline April & 21.276 \\
\hline Mei & 21.492 \\
\hline Juni & 20.412 \\
\hline Juli & 21.420 \\
\hline Agustus & 24.120 \\
\hline September & 25.992 \\
\hline Oktober & 25.380 \\
\hline November & 21.924 \\
\hline Desember & 17.100 \\
\hline
\end{tabular}

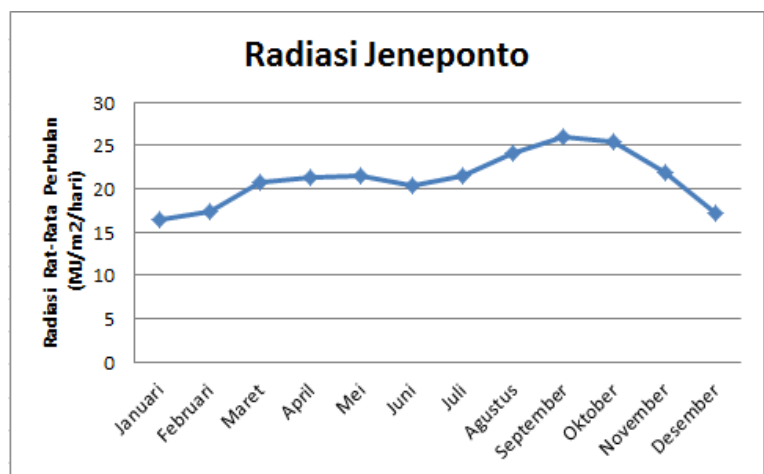

Gambar 5. Grafik radiasi di jeneponto

Dari Gambar 5 dapat dilihat bahwa pada daerah Jeneponto memiliki nilai radiasi paling tinggi di bulan September yaitu mencapai 25.992 $\mathrm{MJ} / \mathrm{m}^{2} /$ hari dan nilai radiasi paling rendah di bulan Januari yaitu mencapai $16.452 \mathrm{MJ} / \mathrm{m}^{2} / \mathrm{hari}$.

Persamaan (2) dan (4) telah diselesaikan dengan menggunakan MATLAB. Persamaan (2) dan (4) dapat dipecahkan tergantung pada nilai awal dari temperatur yang tidak diketahui $T u$ dan Ts. Nilai awal ini berbeda dengan lokasi kolam dan waktu dari tahun ketika solar pond mulai bekerja. Nilai konstanta yang digunakan dalam model adalah sebagai berikut; $\rho u=1000 \mathrm{~kg} / \mathrm{m}^{3}$, $\rho_{l}=1200 \mathrm{~kg} / \mathrm{m}^{3}, c_{p \mathrm{u}}=4180 \mathrm{~J} / \mathrm{kg} \mathrm{K}, c_{p l}=3300$ 
$\mathrm{J} / \mathrm{kg} \mathrm{K}, A_{u}=A_{l}=A b=1 \mathrm{~m}^{2}, h_{1}=56.58, h_{2}=$ $48.279, h_{3}=78.12, h_{4}=185$ (dengan satuan nilai $\left.\mathrm{W} / \mathrm{m}^{2} \mathrm{~K}\right)$ dan $k_{w}=0.596 \mathrm{~W} / \mathrm{m} \mathrm{K}, T_{g}=23{ }^{\circ} \mathrm{C}$. Untuk nlai $x_{g}$ and $k_{g}$ tergantung pada sifat tanah dibawah kolam [8].

Pada Gambar 6 menunjukkan temperatur storage zone selama setahun di daerah Jeneponto.

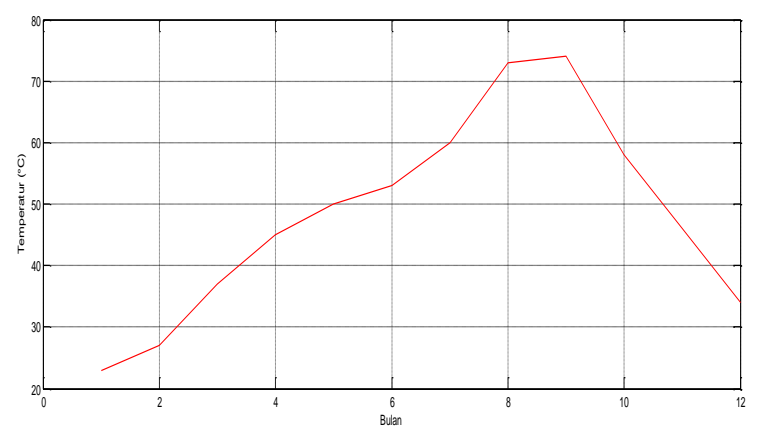

Gambar 6. Grafik temperatur storage zone di jeneponto

Dari Gambar 6 dapat dilihat bahwa temperatur maksimum pada storage zone (LCZ) untuk daerah Jeneponto berada di bulan Agustus sampai September yang berkisar $73{ }^{\circ} \mathrm{C}$ sampai $74{ }^{\circ} \mathrm{C}$. Sedangkan suhu minimum pada storage zone (LCZ) berada di bulan Januari sampai Februari yang berkisar antara $23{ }^{\circ} \mathrm{C}$ sampai 27 ${ }^{\circ} \mathrm{C}$. Dengan suhu storage zone (LCZ) yang berada diatas $70{ }^{\circ} \mathrm{C}$ maka solar pond tersebut sudah bisa digunakan sesuai pemanfaatannya.

\section{Kesimpulan}

Penelitian ini menyoroti lokasi di Sulawesi Selatan tepatnya di Jeneponto yang merupakan daerah penghasil garam dan memiliki potensi panas untuk dieksplorasi. Berdasarkan hasil penelitian dapat disimpulkan bahwa daerah Jeneponto memiliki potensi yang baik sebagai penempatan dari solar pond. Jeneponto memiliki nilai rata-rata maksimum irradiance 25.992 $\mathrm{MJ} / \mathrm{m}^{2} /$ hari dan suhu pada storage zone mencapai $74^{\circ} \mathrm{C}$. Dengan demikian panas yang dihasilkan tersebut dapat digunakan di berbagai bidang seperti pembangkit energi listrik, proses pemanasan industri, desalinasi dan pemanasan konversi biomass.

\section{Ucapan Terimakasih}

Penulis menyadari bahwa penyusunan penelitian ini banyak mengalami hambatan, rintangan dan halangan, namun dengan bantuan dari berbagai pihak semua ini dapat terselesaikan dengan baik, oleh karena itu, pada kesempatan ini penulis menyampaikan rasa terima kasih dan penghargaan yang setinggi-tingginya kepada Bapak Indar Chaerah Gunadin dan Bapak Yusran, selaku pembimbing yang banyak meluangkan waktunya dalam memberikan petunjuk dan bimbingan sehingga kesulitan penulis dalam menyelesaikan penelitian ini dapat terselesaikan. Terimakasih juga yang sebesarbesarnya kepada Bapak dan Ibu Dosen yang telah memberikan banyak masukan dan bimbingannya selama penulis menempuh perkuliahan, dan terimakasih juga kepada suami atas doa dan dukungannya, dan juga terimakasih buat semua teman-teman yang selalu membantu dan dukungannya selama penulis menempuh perkuliahan dan penelitian.

\section{Referensi}

[1] Ahmad Aizaz, Rizwan Yousaf. 2013. Construction and Analysis of A Salt Gradien Solar Pond for Hot Water Supply. European Scientific Journal Edition volume 9 no.36. ISSN 1857-7881.

[2] Khaterin I, Bambang I.W, Ridho H.M, M. Awan E.S. 2013. Studi Pemanfaatan Closed Cycle Salt Gradien Solar Pond (CCSGSP) Untuk Pembangkit Listrik di Pesisir Kabupaten Gresik. Institut Teknologi Sepuluh November

[3] Jerome Godwin Egbe, Ahmed Hasan Khan, Wongsakorn Wisatesajja. 2013. Design of Solar Pond calculation and Technique in Africa. IOSR-JMCE Volume 6 (2013), PP 22-32.

[4] Sura Tundee, Narong Srihajong, Suparerk Charmongkolpradit. 2013. Electric Power Generation from Solar Pond Using Combination of Thermosyphon and Thermoelectric Modules. ScienceDirect Publisher. Energy Procedia 48 (2014) 453-463.

[5] M.M.O Dah, M. Ouni, A. Guizani, A. Belghith. 2005. Study Of Temperature And Salnity Profiles Development of Solar Pond In Laboratory. ScienceDirect Publisher. Desalination 183 (2005) 179185.

[6] NASA, "Data NASA untuk Kabupaten Jeneponto" diunduh [14 Agustus 2017] melalui https://eosweb.larc.nasa.gov/cgibin/sse/grid.cgi?\&num $=300085 \&$ lat $=$ $5.588 \&$ submit $=$ Submit $\&$ hgt $=100 \& v e g=17 \&$ sitelev $=\&$ email=w_wongsakorn@hotmail.com $\& p=$ grid_id $\& p=s$ 
wvdwncook $\& \mathrm{p}=\mathrm{swv}$ dwn $\& \mathrm{p}=\mathrm{T} 10 \mathrm{M} \& \mathrm{p}=\mathrm{TSKIN} \& \mathrm{p}=$ wspd50m\&p=RH10M \&p=PS\&step=2\&lon=119.565

[7] Assad H. Sayer, Hazim Al-Hussaini, Alasdir N. Campbell. 2016. New Theoretical Modelling Of Heat Transfer In Solar Pond. ScienceDirect Publisher. Solar Energy 125 (2016) 207-218

[8] Safwan Kanan, Jonathan Dewsbury, Gregory F. LaneSerff, Muhammad Asim. 2015. The Effect Of Ground Conditions Under A Solar Pond On The Performance Of A Solar Air-Conditioning System. ScienceDirect Publisher . Energy Procedia 91 (2016) 777-784. 